\title{
The Application of the QR Code for Equipment in Substation Operational Maintenance
}

\author{
Haiping $\mathrm{He}^{1, \mathrm{a}}$, Yu Sun ${ }^{1, \mathrm{~b}}$, Jundong Zhang ${ }^{1, \mathrm{c}}$, Qingling Bo ${ }^{1, \mathrm{~d}}$, Xiaohu Cheng ${ }^{1, \mathrm{e}}$, \\ Fei Teng ${ }^{1, f}$ \\ ${ }^{1}$ Chuzhou power supply company of Anhui Province,Chuzhou, Anhui 239000

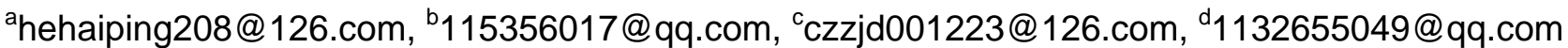 \\ , e476937386@qq.com, ${ }^{\mathrm{f}} 45955903 @ q q . c o m$
}

Keywords: Substation, QR code, Information of equipment, Equipment master system

\begin{abstract}
While the QR code has been used in lots of aspects of people's life, the application of this technology in substation operational maintenance is still in its infancy. The QR code is based on the Equipment Account Management, Defect Management, Maintenance Management and Equipment master system which is the System of Designated Person Responsible for Equipments, and apply the QR code technology in to equipment operational maintenance to realize the improvement of integration of operation and maintenance of the substation. Achieve the further development of operation and maintenance by working actively and enhancing the employee's sense of ownership to realize the information sharing, equipment condominium and the mutual improvement of skill mastery for sure.
\end{abstract}

\section{Introduction}

The staff need to search for the information of equipments before starting their work every time by using the Equipment Information Form or the Production Management System(PMS). Although the Equipment Information Forms are saved orderly, it is still difficult to search for the relative information while the amount of data is gigantic. The second way is searching by using the Production Management System through the computer in the control room while it requires a higher level of the computer and intranet. Considering the experience about the work in the past, it is imperative for the staff to get information of the equipment soon no matter for operation or maintenance. Facing the growing scale of power grid and increasing the number of devices, how to control the equipment information, to better carry out the work, becoming the focus of the operation and maintenance personnel.

\section{QR Code Technology}

The QR code is always a concern of many countries as a brand new technology for the information storage, transmission and recognition since it is invented. The QR code is widely used in credential administration by the police, diplomatic departments and the military; the management of statements and receipts by the customs and tax department; the management of transportation of goods by the transportation department; the management of parcel by the postal department and the automated management in industrial production field[1]. The Chongqing Electric Power Transmission and Transformation Corporation has successfully apply the QR code identification technology as a new method into the management of material and equipment in Longxingbei Transformer Substation for the field staff to use.In traditional project management, project material ledger heavy, huge amount of data loaded down with trivial details, materials, staff at the scene checked one by one information materials and the use of, the workload is very large[2]. And the two-dimensional code software installed by the phone, you can carry a mobile phone, the scene of all kinds of materials to clean up the inventory, improve work efficiency. The QR code technology is simple, just use the phone to install scan software face gently sweep posted on gcgid (field staff card 
or site material QR code identifier), will be able to personnel at the scene belongs unit, type of work category, material specifications and test time important information reflected in the phone screen, greatly enhancing the on-site project department on human, material, machine and management order and convenience[3].

\section{The Traditional Methods to Searching the Information of Equipments}

The following paragraph will focus on the reason why it takes a long time for staff to search for the information of equipment and then analysis the drawbacks of the traditional methods.

\subsection{For operating personnel}

For example, the following table 1 will show the time which is taken to search the information by using the PMS or in the data room in the Fuxiao Substations of Chuzhou power supply company.

Table 1 Time tables for searching information of equipment

\begin{tabular}{|c|c|c|c|c|c|c|c|c|}
\hline \multirow[b]{2}{*}{$\begin{array}{l}\text { Num- } \\
\text { ble }\end{array}$} & \multirow[b]{2}{*}{$\begin{array}{l}\text { Transformer } \\
\text { Substation }\end{array}$} & \multirow[b]{2}{*}{$\begin{array}{l}\text { Whole } \\
\text { time for } \\
\text { patrolling } \\
\text { (min) }\end{array}$} & \multicolumn{3}{|c|}{ Searching by using PMS } & \multicolumn{3}{|c|}{ Searching in the data room } \\
\hline & & & $\begin{array}{c}\text { Folded } \\
\text { back } \\
\text { and } \\
\text { forth } \\
\text { (min) }\end{array}$ & $\begin{array}{l}\text { Searc- } \\
\text { hing } \\
\text { (min) }\end{array}$ & $\begin{array}{l}\text { Propo- } \\
\text { rtion }\end{array}$ & $\begin{array}{c}\text { Folded } \\
\text { back } \\
\text { and } \\
\text { forth } \\
\text { (min) }\end{array}$ & $\begin{array}{c}\text { Searc- } \\
\text { hing } \\
\text { (min) }\end{array}$ & $\begin{array}{l}\text { Propo- } \\
\text { rtion }\end{array}$ \\
\hline 1 & 220kV Dingyuan & 55 & 5 & 8 & $23.6 \%$ & 5 & 10 & $27.3 \%$ \\
\hline 2 & 110kV Jiangxing & 32 & 3 & 4 & $21.9 \%$ & 3 & 7 & $31.2 \%$ \\
\hline 3 & 110kV Quyang & 35 & 3 & 4 & $20 \%$ & 3 & 7 & $28.6 \%$ \\
\hline 4 & 110kV Zhangqiao & 34 & 4 & 4 & $23.5 \%$ & 4 & 7 & $32.3 \%$ \\
\hline 5 & 110kV Shuangtang & 30 & 4 & 3 & $23.3 \%$ & 4 & 6 & $33.3 \%$ \\
\hline 6 & 110kV Luqiao & 41 & 5 & 5 & $24.4 \%$ & 5 & 10 & $36.7 \%$ \\
\hline
\end{tabular}

Which can be found out by the table 1 is that the using PMS is more efficient than searching in the data room. Because of this, the PMS becoming a normal choice to searching for the information. However, it still takes $2 \mathrm{~min}$ for each device and 40 in total for the whole substation. This time might be longer caused by some other factors such as the lack of responsibility, the slow operational speed of the computer, the lack of relative information and so on. It is obvious that the time for searching take a considerable part of the whole time for patrolling, about 23\%, which slow down the efficiency. If the traditional methods are still being used to searching, it must disturb the staff from making the judgment, increase the required time and the workload.

\subsection{For maintenance personnel}

Likewise, the time of maintenance which is taken in Dingyuan Transformer Substation between Jun 2013 and Jun 2015 will be shown in the table 2 base on using the PMS. Through the time on the record, the searching also takes a considerable part, about $12 \%$, of the whole time for maintenance. It is inconvenient for maintenance personnel and cost them more time because they need not only the detailed parameters of the equipment but also the maintenance record in past few years and the present operation situation. It can also present difficulties in cooperation.

Table 2 Time tables for searching maintenance record in Dingyuan Transformer Substation

\begin{tabular}{ccccc}
\hline Numble & Maintenance equipment & $\begin{array}{c}\text { Searching } \\
(\mathrm{min})\end{array}$ & $\begin{array}{c}\text { Whole time for } \\
\text { maintenance(min) }\end{array}$ & Proportion \\
\hline 1 & Disconnectors of Quyangxian & 15 & 189 & $10 \%$ \\
2 & Circuit breaker of Dingqing & 17 & 142 & $12 \%$ \\
3 & $\begin{array}{c}\text { Circuit breaker of Yongkang } \\
\text { Optical fiber longitudinal }\end{array}$ & 12 & 135 & $10 \%$ \\
4 & $\begin{array}{c}\text { differential protection of } \\
\text { Dingqing }\end{array}$ & 19 & 118 & $16 \%$ \\
5 & Microcomputer protection screen \\
of Dingsang & 12 & 105 & $13 \%$ \\
\hline
\end{tabular}


Considering the above research, analysis and site situation, the possible reasons which cost staffs more time in operation and maintenance could be the following several reasons:

a. Limited by nature term such the snowstorm, ice disaster or insufficient light may cause difficulties in recognizing the relevant nameplate information.

b. Within a $220 \mathrm{kV}$ substation, the efficiency is also limited by the distance to the control room which costs 5 for a turn. The slow operational speed of the computer can bring inconvenience in searching process.

c. The PMS needs to get off the line for maintenance upgrade from time to time which could affect the efficiency of searching data.

d. The nameplates are set in a high location which means people need a climb ladder to get to. It is inconvenient and wastes time.

e. Due to natural wear and tear, the definition of nameplates be affected deeply. The unexpected sticking may disturb personnel from recognizing the corresponding information.

With the development of economy, the demand of electrical power will keep increase. Both the increase and the aging problem will bring more workload which ask for an improvement in maintenance efficiency to make sure the power system work safely.

\section{QR Code for Equipment}

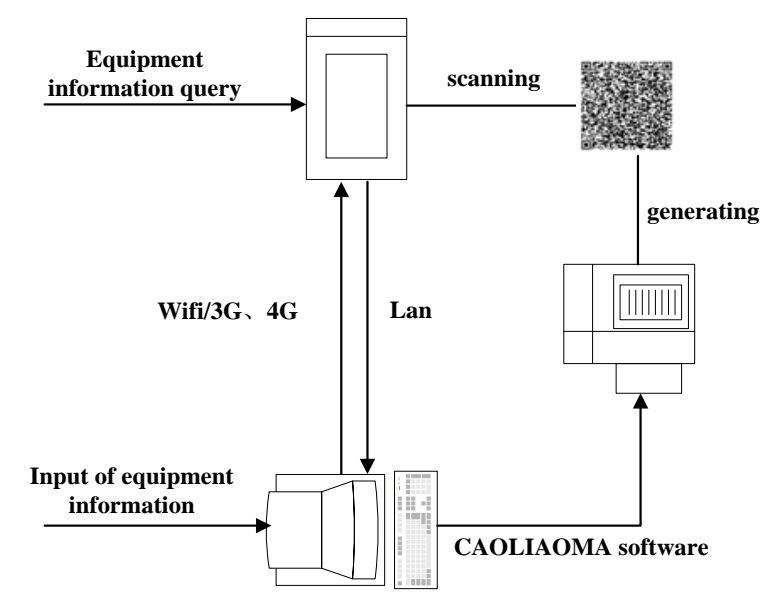

Fig. 1 The production process of the QR code for equipment

Combining with the two dimensional coding technology and mobile terminal technology, the real time management can be realized base the existing information system through the mobile terminal. Collect the relevant information from the existing Production Management System and code it into a unique QR code through the corresponding information system and QR Code Generator. Then print it on a nameplate which made of the stainless steel so that it can be recognized by the mobile terminal during the operation and maintenance. The whole process is shown in Figure 1 and can be divided into the following several steps.

a. Output the detail information(underlying parameter, defect record, maintenance record, experimental report and etc.) of the device and manage it into a txt file or MS Word, Excel file so that it can be read by using the mobile terminal, including images and texts.

b. Download the CAOLIAOMA software and get familiar with it.

c. According to guidance for the establishment of a sound safety equipment owner responsibility system in Anhui power supply company (Trial), the information about the System of Designated Person Responsible for Equipments will be integrated as well which includes the person who is in charge of the operation, maintenance and their contact information. As shown in Fig 2.

d. Because of the confidentiality of the substation information, these QR code will be encrypted to avoid the leakage of these data. As shown in Fig 3.

e. For the information part, to get more information and a user-friendly interface, a link will be created and integrated into the QR code which is connect to an address which stores the information about the equipment underlying parameters, defect record, maintenance record, experimental report. 
f.Because all the files including the equipment underlying parameters, defect record, maintenance record, experimental report are saved in MS Word or MS Excel form, The mobile terminal must have a MS Office function to read these files.

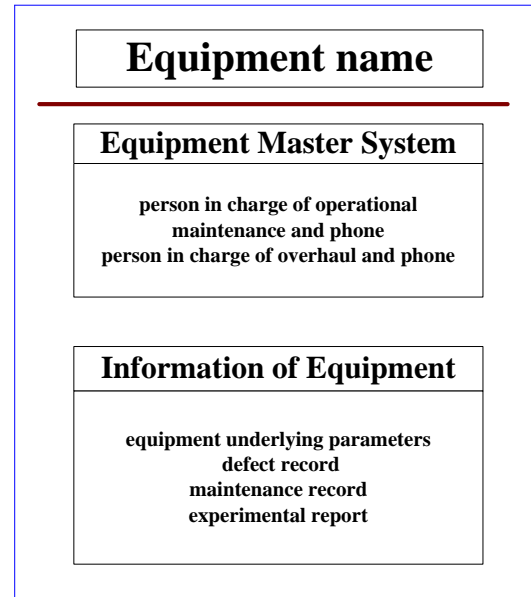

Fig. 2 Main interface of the QR code for equipment information

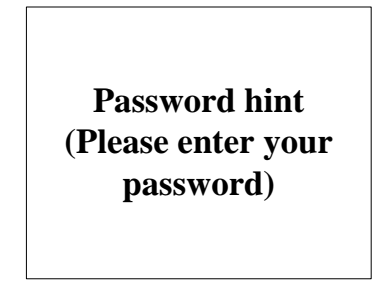

Fig. 3 Prompt for password

\section{The Application of the QR Code for Equipment in Substation Operational Maintenance}

If The QR code has been applied in the the Fuxiao Substations of Chuzhou power supply company and actual application effect is good. Use the same example, the time which is taken after applying the QR code recognition technology is shown in the following Table 3

Comparing with the Table 1, it can be found out that the searching time is reduced obviously which only takes about $2 \%$ of the whole process. It also saves the time in walking between the equipments and the control room to improve both the work efficiency and quality.

At the same time, the follow-up survey to the maintenance work in December in the substation, the reaction from the personnel is good. One item of the maintenance shows that only 1.2 minutes are used in searching information which takes about 1\% of the whole time 115 minutes.

Table 3 Time tables for searching information of equipment by scanning QR code

\begin{tabular}{ccccc}
\hline \multirow{2}{*}{ Numble } & \multirow{2}{*}{$\begin{array}{c}\text { Transformer } \\
\text { Substation }\end{array}$} & $\begin{array}{c}\text { Whole time } \\
\text { for patrolling } \\
\end{array}$ & & \multicolumn{2}{c}{$\begin{array}{c}\text { Searching by scanning } \\
\text { QRin) }\end{array}$} & $\begin{array}{c}\text { Searching } \\
(\mathrm{min})\end{array}$ & Proportion \\
\hline 1 & $220 \mathrm{kV}$ Dingyuan & 55 & 1.6 & $2.4 \%$ \\
2 & $110 \mathrm{kV}$ Jiangxing & 32 & 0.7 & $2.1 \%$ \\
3 & $110 \mathrm{kV}$ Quyang & 35 & 0.6 & $1.7 \%$ \\
4 & $110 \mathrm{kV}$ Zhangqiao & 34 & 0.6 & $1.7 \%$ \\
5 & $110 \mathrm{kV}$ Shuangtang & 30 & 0.5 & $1.7 \%$ \\
6 & $110 \mathrm{kV}$ Luqiao & 41 & 0.8 & $1.9 \%$ \\
\hline
\end{tabular}

\section{Conclusion}

With the proliferation of smart phones and application of QR code technology, both of them will bring great benefits to the Substation Operational Maintenance to deal with the problem of lack of human resources. It can improve the efficiency and save more for other operational maintenance work. This technology is also helpful to reduce the time of off-line maintenance so that it can improve the service quality of power supply and reduce the loss of power supply caused by off-line maintenance. All these advantages will finally bring a considerable economic and social benefits to the society. 


\section{References}

[1]. Hu Pingwang, Huang Ronggui, Gu Keqing, et al. Research into Application of 2D-Barcode Technology to Vehicle Information Management System[J]. Computer and communications,2006. 20(6): 57-58.

[2]. Yang Feijin, Lin Zhen, Ye Wei, Chen Xuyan, Zhou Guoqing et al. Mobile QR code used in the electrical secondary equipment spare parts management[J]. Water Conservancy \& Electric Power Machinery, 2013. 35(6): 45-46.

[3]. Ren Xiaoyu. QR code in substation electrical installations[J]. Modern Business Trade Industry, 2013. 08: 183-184 